\title{
Erratum to: Internet Use and Subjective Well-Being in China
}

\author{
${\text { Peng } \text { Nie }^{1} \cdot \text { Galit Nimrod }^{2} \cdot \text { Alfonso Sousa-Poza }}^{1}$
}

\section{Erratum to: Soc Indic Res \\ DOI 10.1007/s11205-015-1227-8}

Unfortunately, in the original publication of the article, the order of authors was interchanged. Hence the correct order of authors is included in this erratum.

The online version of the original article can be found under doi:10.1007/s11205-015-1227-8.

Peng Nie

Peng_Nie@uni-hohenheim.de

Galit Nimrod

gnimrod@bgu.ac.il

Alfonso Sousa-Poza

alfonso.sousa-poza@uni-hohenheim.de

1 Institute for Health Care and Public Management, University of Hohenheim, 70599 Stuttgart, Germany

2 Department of Communication Studies, The Center for Multidisciplinary Research in Aging, BenGurion University of the Negev, Beersheba, Israel 